\title{
Sesame Phyllody Disease: Symptomatology and Disease Incidence
}

\author{
J. Vamshi ${ }^{1^{*}}$, G. Uma Devi ${ }^{2 *}$, S. Chander Rao ${ }^{2}$ and G. Sridevi ${ }^{3}$ \\ ${ }^{1}$ Department of Plant Pathology, ${ }^{3}$ Department of Entomology, College of Agriculture, \\ Professor Jayashanker Telangana State Agriculture University, \\ Rajendranagar, Hyderabad, Telangana, India \\ ${ }^{2}$ ICAR-Indian Institute of Oilseeds Research, Rajendranagar, Hyderabad, Telangana, India \\ *Corresponding author
}

\section{Keywords \\ Phyllody, Virescence, Genotypes, Witches broom, Vivipary and Phytoplasma}

Article Info

Accepted:

18 September 2018 Available Online: 10 October 2018

\section{A B S T R A C T}

Phyllody is a serious disease of sesame caused by phytoplasma. Different types of disease symptoms are reported to be associated with sesame phyllody. The major symptoms are phyllody, Flower virescence, witches broom, shoot tip fasciation, flattening of the shoot apex and cracking of seed capsules. In addition to this, infected plants exhibit reduction of internode distance and of leaf size. Investigations were carried out on the symptomatology of phytoplasma associated with phyllody disease. Twenty genotypes were evaluated for per cent disease incidence, variation with the types of symptoms and disease score in field conditions. Among twenty genotypes two genotypes 17) ES-62 and 5) 12-JUN were found with zero per cent disease incidence resistant to phyllody disease. The disease incidence ranged from 12.5 percent (5-SAVITHRI) to a maximum of 66.66 per cent (26) SI-1687-1). The development of symptoms was also studied from 30 to 60 days after sowing where in none of genotypes produced symptoms at 30DAS, however from 45th day onwards symptoms were observed in all the genotypes except in 3 genotypes, 17) ES-62 and 5) 12JUN did not produce any symptoms even at 60DAS. 11 Genotypes showed only phyllody symptoms, 2 genotypes produced witches broom symptom, while 2 genotypes showed phyllody as well as twisting of stem. Cracking of capsule was observed in genotype 24) JLT-408, while vivipary and phyllody symptom was observed in genotype 17) RT-351. Among 20 genotypes 17) ES-62 and 5) 12-JUN ranked as highly resistant and 4 genotypes ranked as moderately resistant.

\section{Introduction}

Sesame (Sesamum indicum L.) is an important oil seed crop of India preferred due to rich in its edible oil content (about 50\%) and nutritious protein (about 23\%) and having sufficient carbohydrate (15\%) (Ranganatha et al., 2012). The medical value of sesame seeds are accepted worldwide due to the rich source of linoleic acid, Vitamin E, A, B1 and B2 (Brar and Ahuja,1979). The presence of antioxidants (seasmin, seasminol, sesamolin) in sesame seeds increase many fold the medicinal value (Bedigian, 1985; Moazzami, 2006; El-Bramway and Mahesh, 2010). The crop is cultivated in a wide range of 
atmospheres, extending from semi-arid tropics and sub-tropics to temperate areas of the world (Raikwar and Srivastava, 2013). India is the leading producer of sesame seeds in the world (FAO, STAT, 2016). In India, sesame crop occupies an area of 19 lakh ha with production of 7.97 lakh tones and productivity of $419 \mathrm{~kg} / \mathrm{ha}$ (FAO STAT, 2016). In Telangana it is cultivated over an area of 0.11 lakh ha with the production of 0.02 lakh MT and productivity of $195 \mathrm{~kg} / \mathrm{ha}$ (Agricultural Action Plan 2016-17).

The major disease affecting sesame are reviewed and documented by Verma (2002). Low and unreliable yields, shattering, high production cost and lower returns to the farmers (Murthy et al., 1985) besides early senescence, photosensitivity and susceptibility to various biotic and abiotic stress (Sudhakar and Sree Rangaswamy, 1989) continue to be the major productivity constraints in sesame.

Sesame (Sesamum indicum L.) is under constant threat to many diseases viz., charcoal rot/ stem rot/ root rot, powdery mildew, leaf blight, wilt, leaf spot, stem blight, bacterial leaf spot and phyllody. Among all the diseases the economically important disease affecting sesamum is phyllody, considered to be caused by a virus which was later confirmed as mycoplasma like organisms (MLO), and recently termed as phytoplasmas (Das and Mitra, 1998) which takes a heavy toll resulting in significant yield losses.

Phytoplasmas (Mycoplasma - like organisms) are specialized bacteria which do not have cell wall are obligate parasites found in sieve elements of plants and some insect vector. They are transmitted from one plant to another by phloem feeding insects, leafhopper, plant hoppers and psyllids. Yellow disease of plant presumed earlier to be caused by virus, however could not be visualized in affected plants (Lee and Davis 1992). Japanese scientists were the first to describe phytoplasma as the plant pathogens responsible for yellow disease (Doi et al., 1967)

Phytoplasma are surrounded by a single-unit membrane, lack rigid cell wall, pleomorphic in shape with an average diameter of $0.2-0.8 \mu \mathrm{m}$ (Doi et al., 1967; McCoy et al., 1989) and transmitted by sap sucking insect vectors belonging to the families Cicadellidea (leaf hopper) and Fulgoridea (plant hopper) (Banttari and Zeyea, 1979), vegetative propagation through grafts, cuttings, storage tuber, rhizome or bulb (Lee and Davis, 1992). However, unlike viruses they are not transmitted mechanically by inoculation with phytoplasma containing sap from affected plants. In host plants they exhibit a range of symptoms as phyllody, floral virescence, sterility of flowers, proliferation of auxiliary shoot resulting in witches ${ }^{\text {ee }}$ broom, generalized stunting, abnormal elongation of internodes resulting in slender shoots.

In recent years incidence of phyllody is increasing in sesame fields of Telangana state. In view of the seriousness of the disease and scarcity of the related information on these phytoplasmas especially on sesamum, the present study on symptomatology of phyllody disease in different genotypes of sesamum was carried out

\section{Materials and Methods}

The experiment was conducted at ICAR Indian Institute of Oilseeds Research field by raising twenty genotypes viz., 4)VRI-SV-2, 5SAVITHRI, 34)INT-155-115, 27)HT-75, 26)SI-1687-1, 28)S-0539, 19)ES-62, 6)TMV, 3) IS-113-A, 23)SWETHA, 31)NIRMALA, 26)GRT-8392, 24)JLT-408, 21)DS-5, 8)THILOTHAMA, 17)RT-351, 17)ES-62, 5)12-JUN, 30)TKG-22 during kharif 2017. The experiment was laid out in augmented 
block design with a spacing of $45 \times 15 \mathrm{~cm}$. Each genotype was sown in a single row of $4 \mathrm{~m}$. Conventional agronomic practices were followed to keep the crop in good condition, however, no plant protection measures were applied against the vector Orosius albicinctus to have high inoculum pressure. Observations on phyllody disease of sesame began one week after germination. Both symptomatic and asymptomatic plants were tagged in the naturally infected fields at different growth stages. These plants were examined for the main and distinguishing symptoms such as (phyllody, virescence, witches broom and capsule breaking) as suggested by Vasudeva (1961), Salehi and Izadpanah (1992).

Data on the incidence of phyllody in each genotype was recorded at 30, 45 and 60 days after sowing by counting the number of infected plants and total population before harvest. Resistance or susceptibility of genotypes was based on the average percentage of plants infected by the disease, following a seven point (0-6) rating scale as given in Table 1 suggested by Akthar et al., 2013.

\section{Results and Discussion}

\section{Symptomatology of phyllody disease in different genotypes of sesamum}

The data on per cent disease incidence was recorded at 30th, 40th and 60th day after sowing of crop and the results are presented in Table 2. Out of twenty genotypes, eighteen genotypes viz., 4)VRI-SV-2, 5-SAVITHRI, 34)INT-155-115, 31)HT-75, 26)SI-1687-1, 28)S-0539, 19)ES-62, 6)TMV, 3)IS-113-A, 23)SWETHA, 31)NIRMALA, 26)GRT-8392, 24)JLT-408, 21)DS-5,8)THILOTHAMA, 17)RT-351, 30)TKG-22 were found susceptible to the disease while two genotypes 17)ES-62 and 5)12-JUN were found resistant to incidence of phyllody. Among the eighteen genotypes 26)SI-1687-1 recorded maximum per cent disease incidence with 66.60 per cent followed by 21)DS-5 (57.14), 23) SWETHA $(55.55 \%)$ and 24)JLT-408 (54.54\%), two genotypes 29)G-TIL-10 and 8)THILOTHAMA showed 50 per cent disease.

The least disease incidence of 12.50 per cent was recorded in the genotype 5-SAVITHRI. Perusal of the data also indicated that at 30 DAS none of the genotypes succumbed to the disease but from 45th day onwards disease was observed in all the genotypes except 17)ES-62 and 5)12-JUN which did not show any symptoms either at 30th, 40th and 60th day after sowing. At 45th day after sowing all the eighteen genotypes showed phyllody symptoms. The symptoms observed were mostly phyllody, witches broom, twisting of the stem, virescence and cracking of the capsules. It was also observed that the symptoms were confined to the upper portion of the plant and with the increase in age of the plant the symptoms were more pronounced. The genotypes also showed variation with the types of symptoms (Table 3). Phyllody (Floral parts converted to leaf like structure), virescence (color change to green), stunting of flowers, abnormal elongation of internodes, proliferation of auxiliary shoot resulting in witches broom, generalized stunting are the symptoms produced in the infected plants. Genotypes 4)VRI-SV-2, 5-SAVITHRI, 34)INT-155-115, 26)SI-1687-1 (Plate 1), 6)TMV, 3)IS-113-A, 23)SWETHA, 31)NIRMALA (Plate 2), 21)DS-5, 8)THILOTHAMA and 30)TKG-22 (Plate 3) showed only phyllody symptoms where the floral parts are converted into leaf like structures.

Genotypes 27)HT-75 and 28)S-0539 (Plate 4) produced witches broom symptom while the genotypes 29)G-TIL-10 and 26)GRT-8392 (Plate 5) showed phyllody as well as twisting 
of stem. Virescence symptom was observed in genotypes 19)ES-62 (Plate 6) along with phyllody symptom. Cracking of capsule was observed in genotypes 24)JLT-408 (Plate 7), while vivipary and phyllody symptom was observed in genotype 17)RT-351 (Plate 8), (Table 3).

Similar symptoms were reported by Vasudeva (1955), Choopanya (1973), Salehi and Izadpanah (1992). Typical phytoplasma symptoms of phyllody, virescence, asymptomatic shoot proliferation, infertile flowers, reduced leaf size and weak capsules on sesamum were also observed by Cengiz et al., (2014) from Turkey.

In the present study major symptoms observed were phyllody produced by most of the genotypes, while witches broom symptoms were produced in genotypes 27)HT-75 and 28)S-0539. Cracking of the capsule and germination of seed within the capsule were also reported in the present study.

The capsule which had set prior to infection usually crack longitudinally and inside capsule the seeds were found to germinate. Salehi and lzadpanah (1992) and Akhtar et al., (2013) also observed similar type of capsule symptoms in sesamum.

Based on per cent disease incidence and disease score the genotypes were categorized from highly resistant to highly susceptible and the results are presented in Table 4.

Data presented in Table 4 indicated that two genotypes 17)ES-62, 5)12-JUN were highly resistant while four genotypes 5-SAVITHRI, 27) HT-75, S-0539, 17)RT-351 were moderately resistant. Only one genotype was found tolerant to the disease with a disease score of 3 while genotypes 34)INT-155-115, 3)IS-113-A, 6)TMV were moderately susceptible. Genotypes 29)G-TIL-10, 19)ES-
62, 31)NIRMALA, 26)GRT-8392, 8)THILOTHAMA, 30)TKG-22 were susceptible and genotypes 24) JLT-408, 21)DS-5, 26)SI-1687-1, 23)SWETHA were highly susceptible. None of the genotypes were found resistant to the disease.

Similar results were obtained by Singh et al., 2007 and Akhtar et al., 2013. Singh et al., 2007 screened 150 genotypes, 32 cultivars and 4 wild species under field conditions and identified seven genotypes and two wild species as resistant.

Similarly Akhtar et al., 2013 screened 133 genotypes belonging to different regions for two consecutive years in 2007 and 2008 and found four genotypes highly resistant to sesamum phyllody.

In the present study difference in the degree of disease reaction was observed among the genotypes. Only two genotypes were highly resistant to sesamum phyllody, while the rest of the genotypes showed disease reaction from moderately resistant to highly susceptible reaction.

Among twenty genotypes two genotypes 17)ES-62 and 5)12-JUN were found with zero per cent disease incidence and found resistant to phyllody disease, while the rest of 18 genotypes were susceptible.

The disease incidence ranged from 12.5 per cent (5-SAVITHRI) to a maximum of 66.66 percent (26)SI-1687-1).

The development of symptoms was also studied from 30 to 60 days after sowing. It was found at 30DAS none of genotypes produced symptoms however from 45th day onwards symptoms were observed in all the genotypes except in 27)HT-75, 17)ES-62 and 5)12-JUN did not produce any symptoms even at 60DAS. 
Table.1 Disease scale for sesamum phyllody (Akhtar et al., 2013)

\begin{tabular}{|r|l|l|}
\hline Rating & Per cent disease incidence & Disease Reaction \\
\hline 0 & No symptoms on any plant & Highly resistant \\
\hline 1 & $0.1-10 \%$ & Resistant \\
\hline 2 & $10.1-20$ & Moderately resistant \\
\hline 3 & $20.1-30$ & Tolerant \\
\hline 4 & $30.1-40$ & Moderately susceptible \\
\hline 5 & $40.1-50$ & Susceptible \\
\hline 6 & More than $50 \%$ & Highly susceptible \\
\hline
\end{tabular}

Table.2 Disease incidence in sesamum genotypes

\begin{tabular}{|c|c|c|c|c|c|c|}
\hline \multirow{3}{*}{ Genotypes } & \multirow{2}{*}{$\begin{array}{l}\text { Number } \\
\text { of plants }\end{array}$} & \multicolumn{2}{|c|}{ Number of } & plants & \multirow{3}{*}{$\begin{array}{l}\text { Total } \\
\text { number of } \\
\text { plants }\end{array}$} & \multirow{3}{*}{$\begin{array}{l}\text { Per cent } \\
\text { disease } \\
\text { incidence }\end{array}$} \\
\hline & & \multicolumn{3}{|c|}{ affected at days after } & & \\
\hline & & sowing & & & & \\
\hline & & & & & affected & $(\%)$ \\
\hline & & 30 & 45 & 60 & & \\
\hline 4)VRI-SV-2 & 5 & - & 1 & - & 1 & 20 \\
\hline 5-SAVITHRI & 8 & - & 1 & - & 1 & 12.5 \\
\hline 34)INT-155-115 & 9 & - & 2 & 1 & 3 & 33.33 \\
\hline 27)HT-75 & 6 & - & - & 1 & 1 & 14.2 \\
\hline 29)G-TIL-10 & 8 & - & 3 & 1 & 4 & 50 \\
\hline 26)SI-1687-1 & 6 & - & 2 & 2 & 4 & 66.66 \\
\hline 28)S-0539 & 12 & - & 1 & 1 & 2 & 16.6 \\
\hline 19)ES-62 & 17 & - & 4 & 3 & 7 & 41.17 \\
\hline 6)TMV & 9 & - & 3 & - & 3 & 33.33 \\
\hline 3)IS-113-A & 8 & - & 2 & 1 & 3 & 37.5 \\
\hline 23)SWETHA & 9 & - & 3 & 2 & 5 & 55.55 \\
\hline
\end{tabular}




\begin{tabular}{|l|l|l|r|r|r|l|}
\hline 31)NIRMALA & 14 & - & 3 & 3 & 6 & 42.8 \\
\hline 26)GRT-8392 & 9 & - & 3 & 1 & 4 & 44.44 \\
\hline 24)JLT-408 & 11 & - & 4 & 2 & 6 & 54.54 \\
\hline 21)DS-5 & 7 & - & 3 & 1 & 4 & 57.14 \\
\hline 8)THILOTHAMA & 12 & - & 5 & 1 & 6 & 50 \\
\hline 17)RT-351 & 7 & - & 1 & - & 1 & 14.2 \\
\hline 17)ES-62 & 15 & - & - & - & - & 0.00 \\
\hline 5)12-JUN & 13 & - & - & - & - & 0.00 \\
\hline 30)TKG-22 & 12 & - & 4 & 1 & 5 & 41.66 \\
\hline
\end{tabular}

Table.3 Symptoms of phyllody in sesamum genotypes

\begin{tabular}{|l|l|l|}
\hline Genotypes & Type of symptom observed & Time of occurrence \\
\hline of symptom (DAS)
\end{tabular}




\begin{tabular}{|l|l|l|}
\hline 3)IS-113-A & Phyllody & 45,60 \\
\hline 23)SWETHA & Phyllody & 45,60 \\
\hline 31)NIRMALA & Phyllody & 45,60 \\
\hline 26)GRT-8392 & Phyllody, twisting of stem & 45,60 \\
\hline 24)JLT-408 & Phyllody, cracking of capsule & 45,60 \\
\hline 21)DS-5 & Phyllody & 45,60 \\
\hline 8)THILOTHAMA & Phyllody & 45,60 \\
\hline 17)RT-351 & Phyllody, vivipary & 45 \\
\hline 30)TKG-22 & Phyllody & 45,60 \\
\hline
\end{tabular}

Table.4 Grouping of sesamum genotypes based on disease reaction

\begin{tabular}{|c|c|c|c|c|}
\hline $\begin{array}{l}\text { Disease } \\
\text { Score }\end{array}$ & Disease reaction & Genotypes & & $\begin{array}{l}\text { Number of } \\
\text { genotypes }\end{array}$ \\
\hline 0 & Highly resistant & 17)ES-62, 5)12-JUN & & 2 \\
\hline 1 & Resistant & - & & - \\
\hline \multirow[t]{2}{*}{2} & Moderately & \multicolumn{2}{|c|}{ 5-SAVITHRI, 27) HT-75, S-0539, } & 4 \\
\hline & resistant & I7)RT- 351 & & \\
\hline 3 & Tolerant & 4)VRl-SV-2 & & 1 \\
\hline \multirow[t]{2}{*}{4} & Moderately & \multicolumn{2}{|c|}{ 34)INT-155-115, 3)IS-113-A, 6)TMV } & 3 \\
\hline & Susceptible & & & \\
\hline \multirow[t]{3}{*}{5} & Susceptible & 29)G-TIL-10, & 19)ES-62, & 6 \\
\hline & & 31)NIRMALA, & 26)GRT-8392, & \\
\hline & & \multicolumn{2}{|c|}{ 8)THILOTHAMA, 30)TKG-22 } & \\
\hline \multirow[t]{2}{*}{6} & Highly & \multicolumn{2}{|c|}{ 24)JLT-408, 21)DS-5, 26)SI-1687-1, } & 4 \\
\hline & Susceptible & 23)SWETHA & & \\
\hline
\end{tabular}




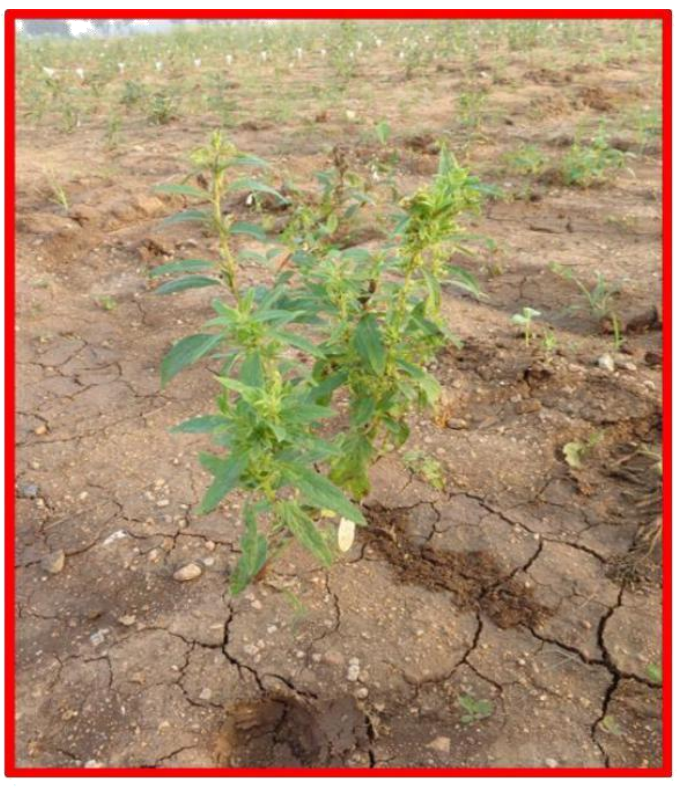

(a)

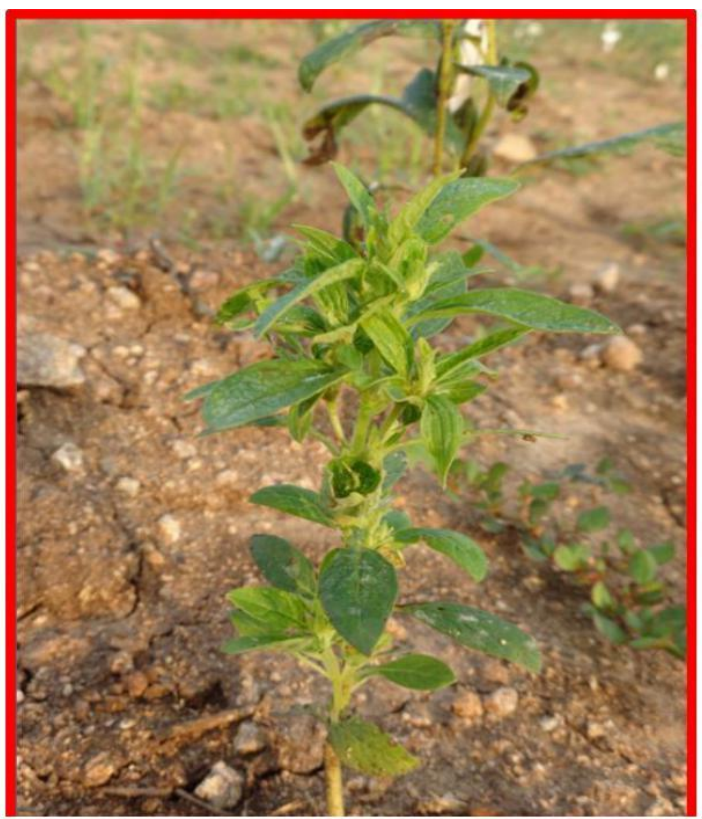

(c)

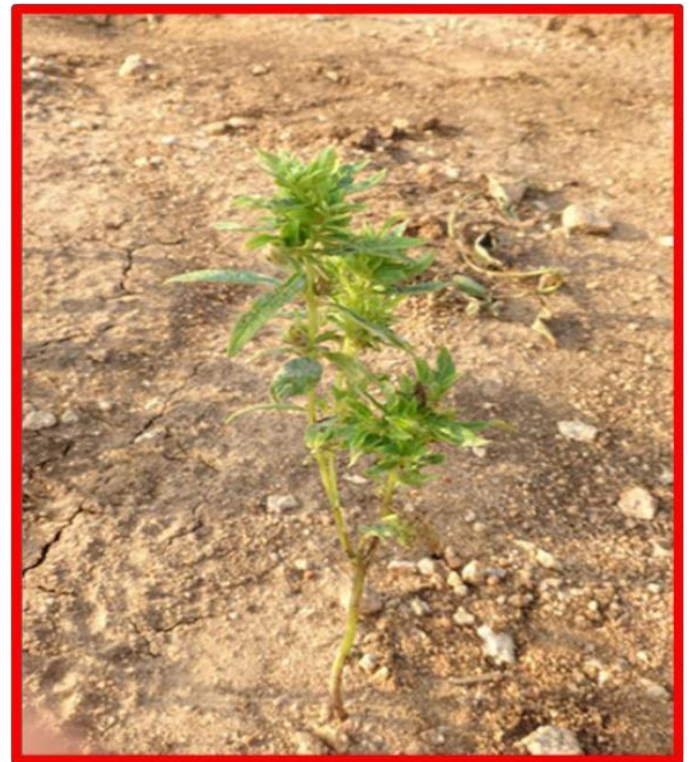

(b)

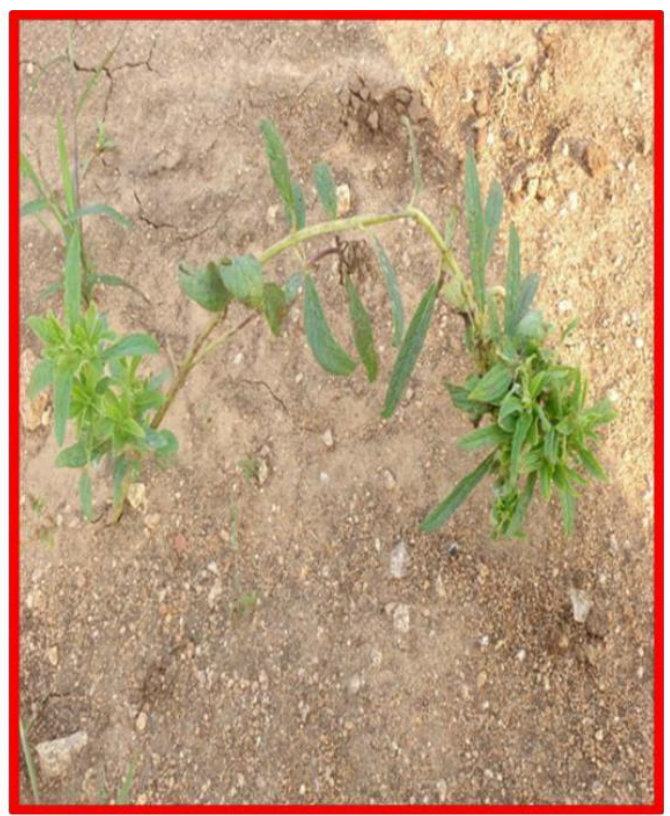

(d)

Plate 1: Symptoms of phyllody in different genotypes of sesamum
a) VRI-SV-2
b) 5-SAVITHRI
c) 34)INT-155-115 d)

26)SI-1687-1 


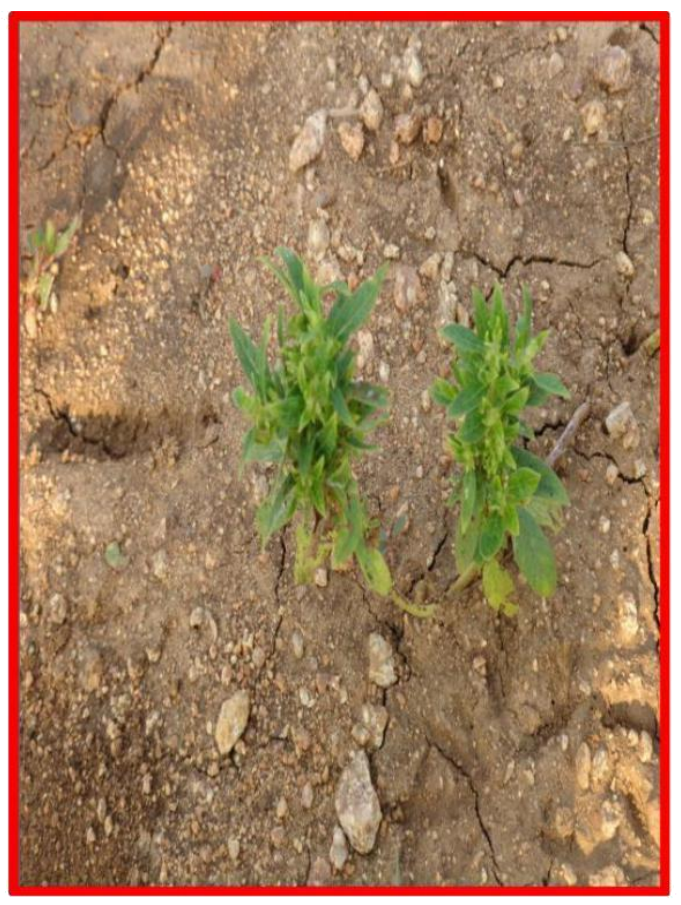

(a)

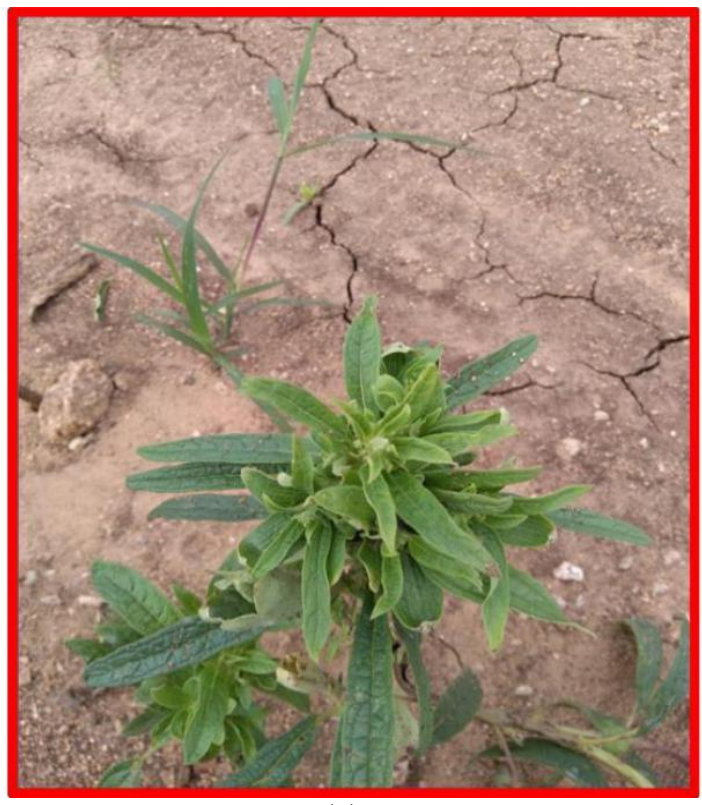

(c)

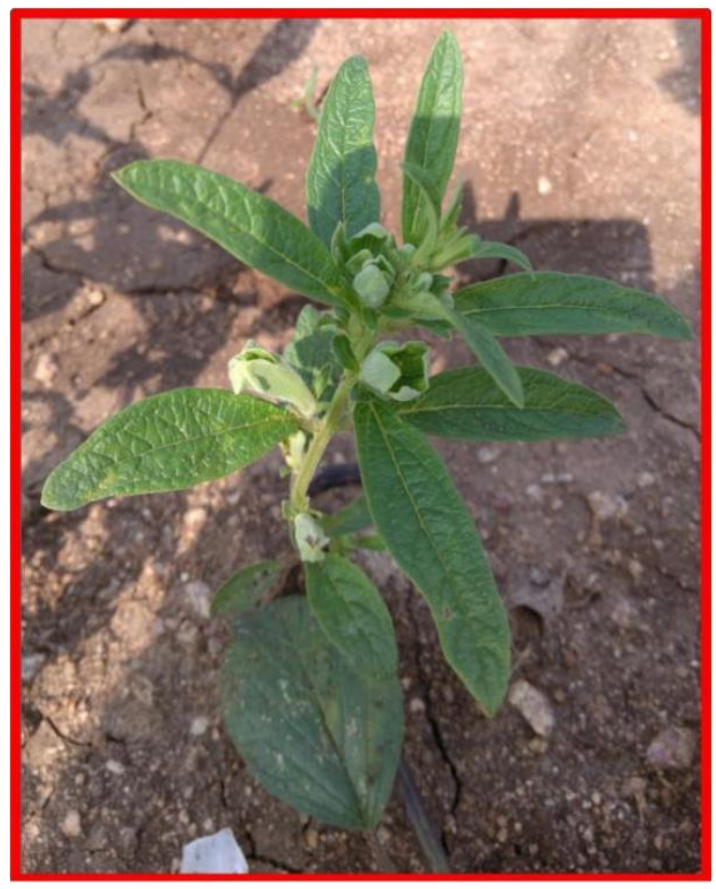

(b)

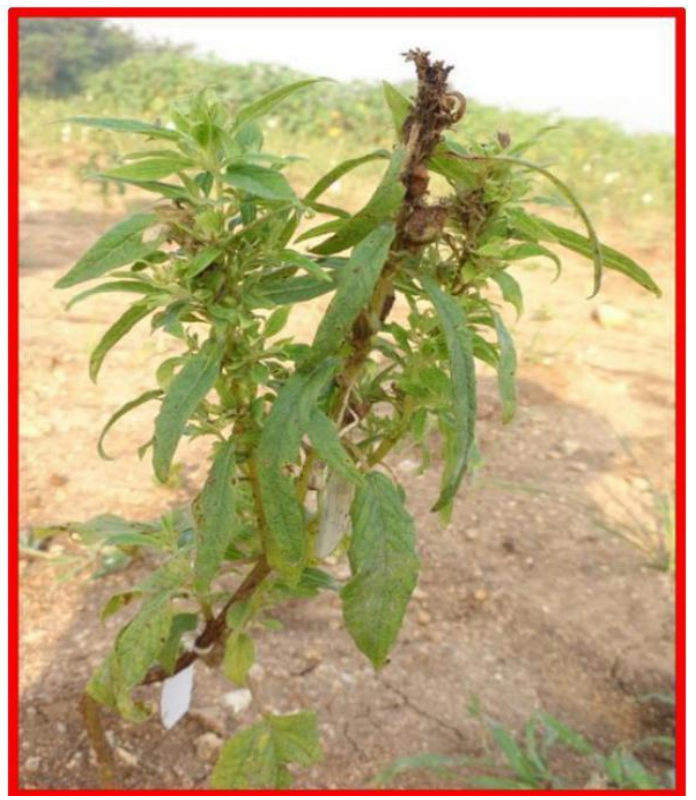

(d)

Plate 2: Symptoms of phyllody in different genotypes of sesamum
a) 6) TMV
b) IS-113-A 


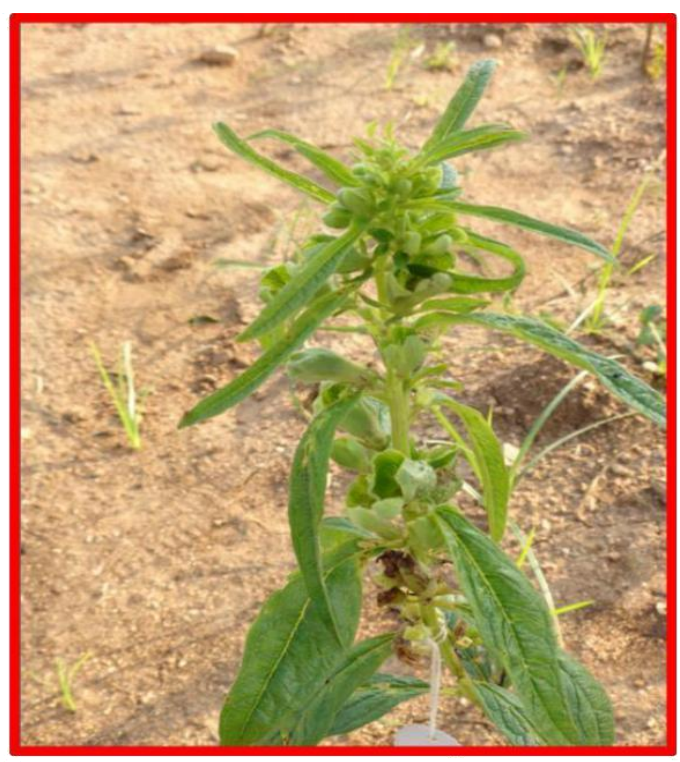

(a)

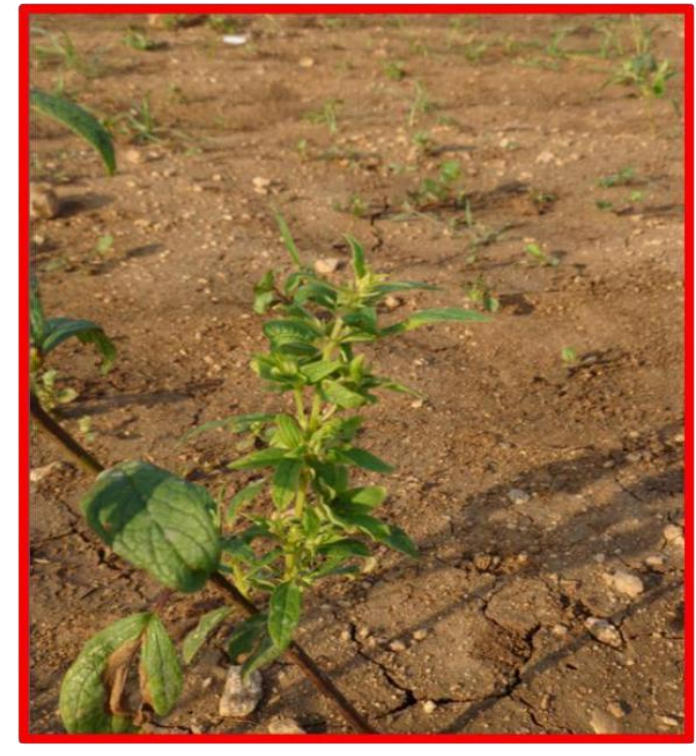

(b)

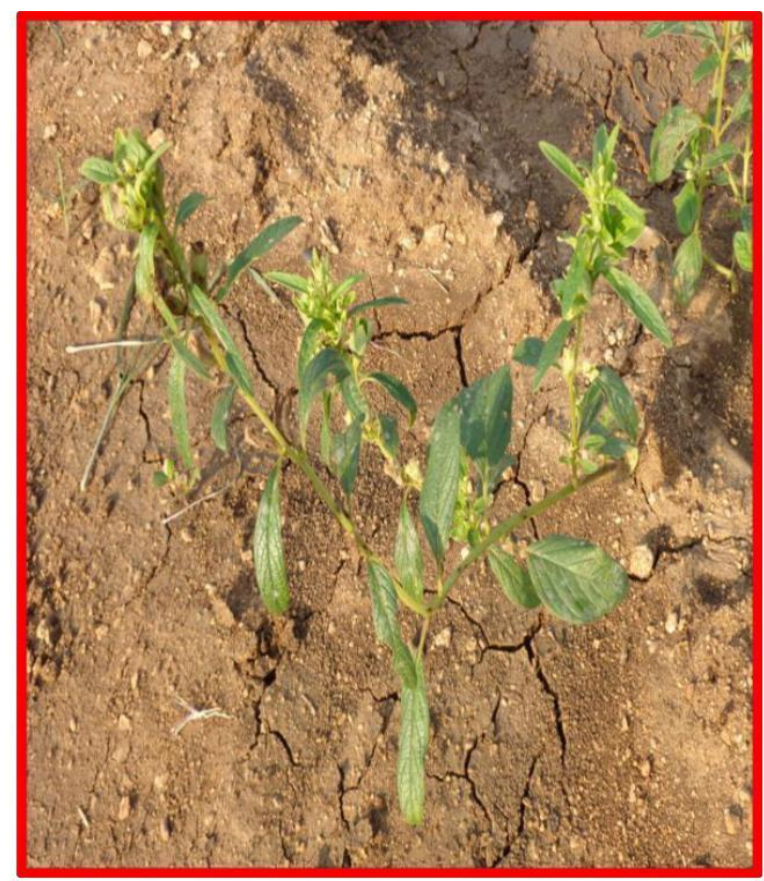

(c)

Plate 3: Symptoms of phyllody in different genotypes of sesamum
a) 21$) \mathrm{DS}-5$
b) 8)THILOTHAMA
c) 30$) \mathrm{TKG}-22$ 


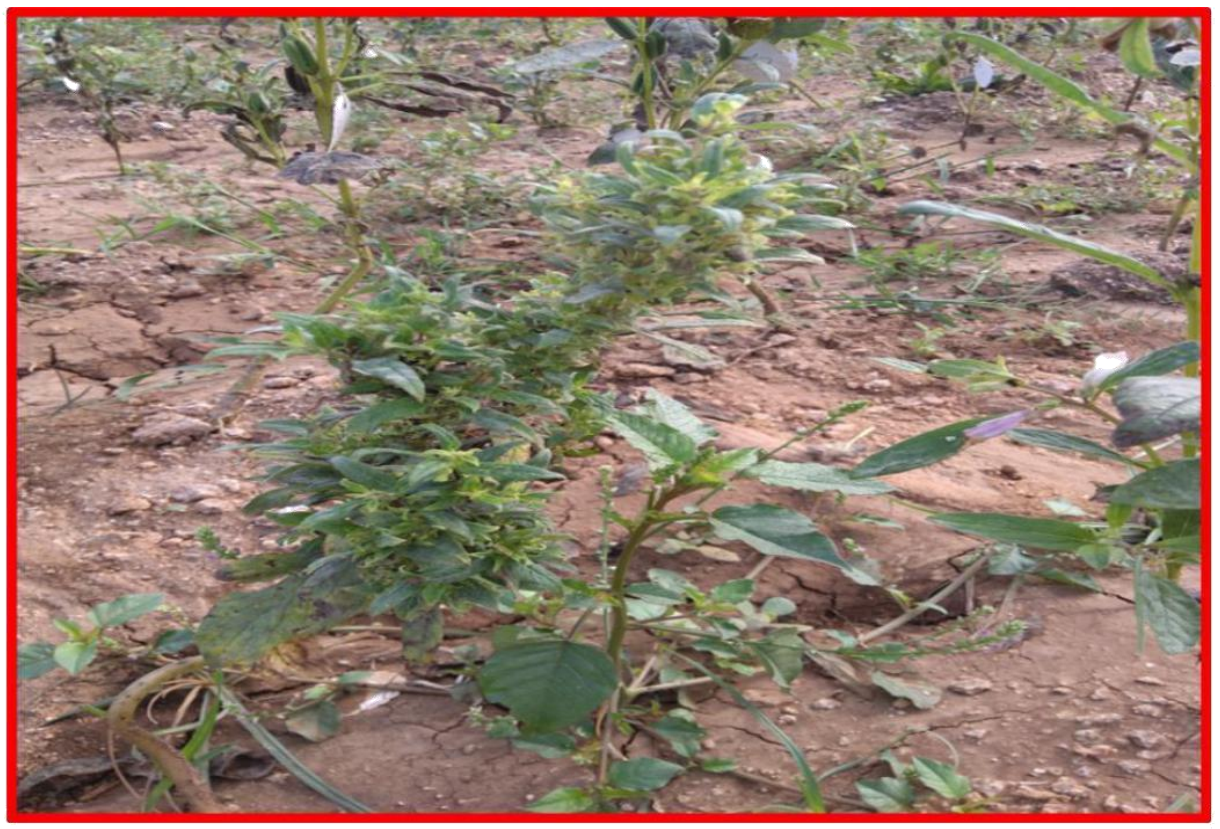

(a)

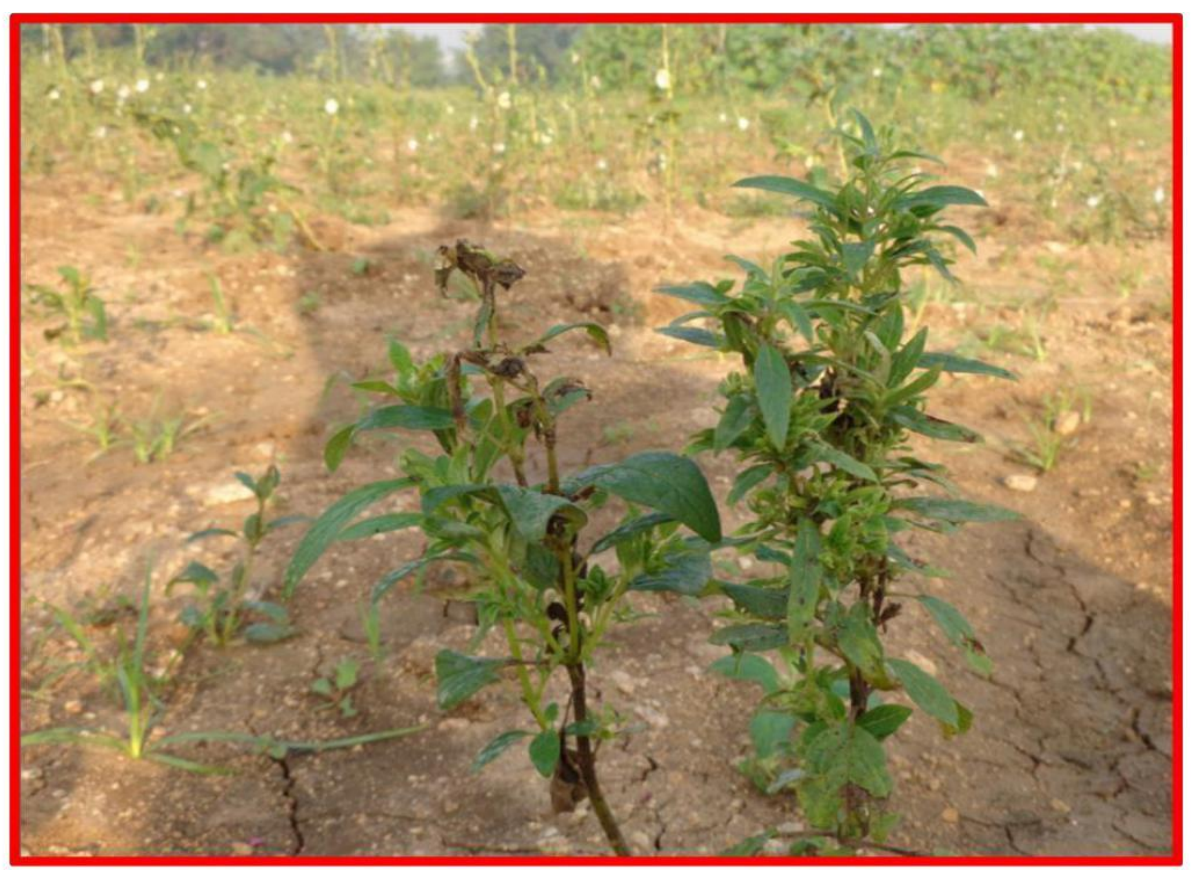

(b)

Plate 4: Symptoms of witches broom in different genotypes of sesamum a)

27)HT-75

b) 28)S-0539 


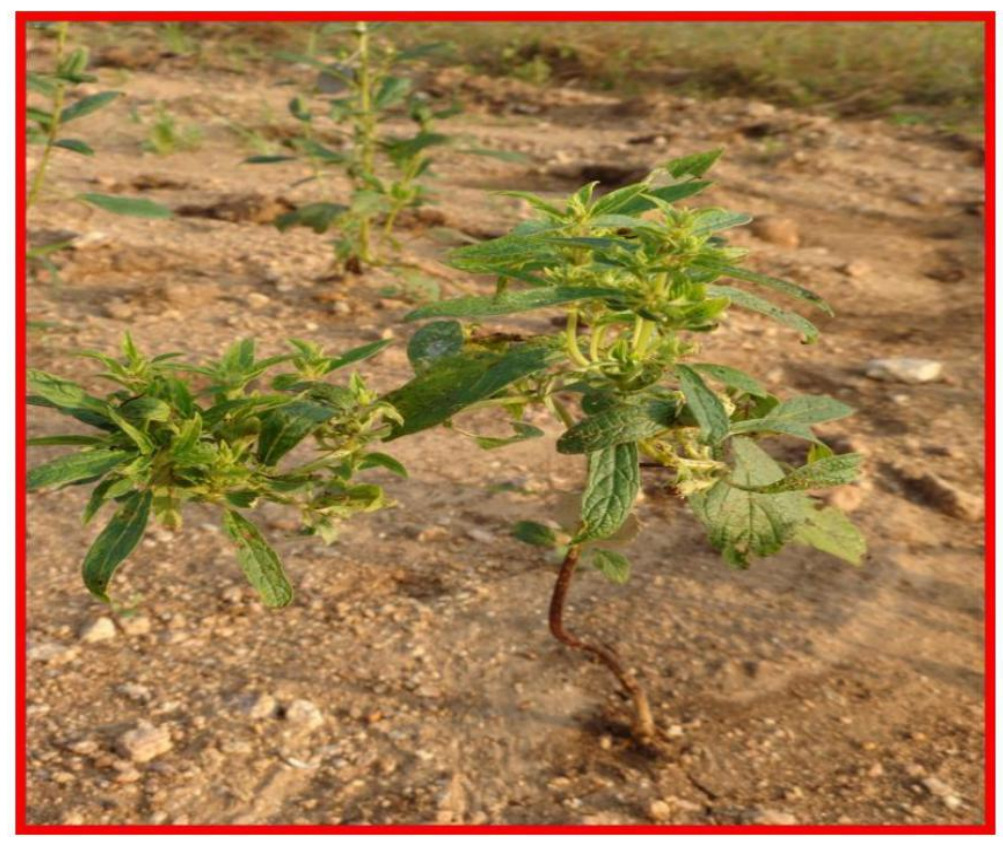

(a)

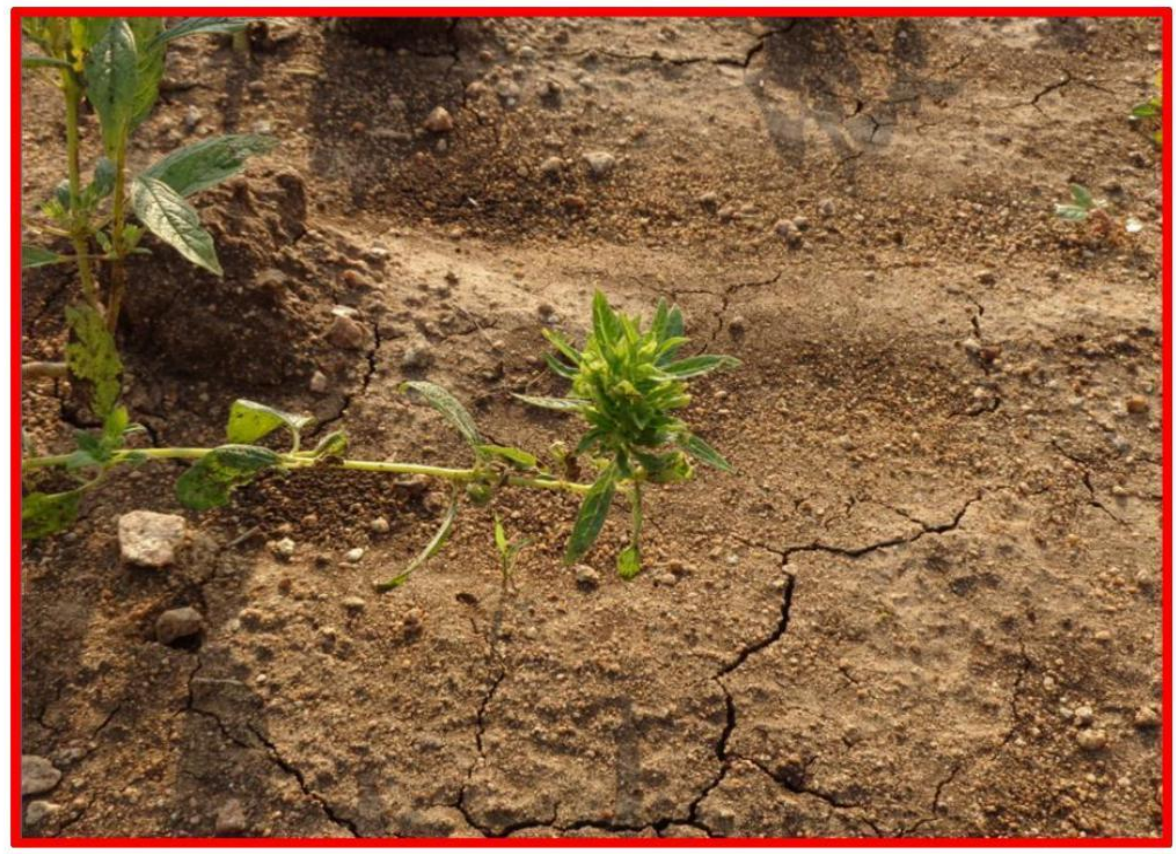

(b)

Plate 5: Genotypes of sesamum showing both phyllody and twisting of stem a) 29)G-TIL-10

b) 26)GRT-8392 


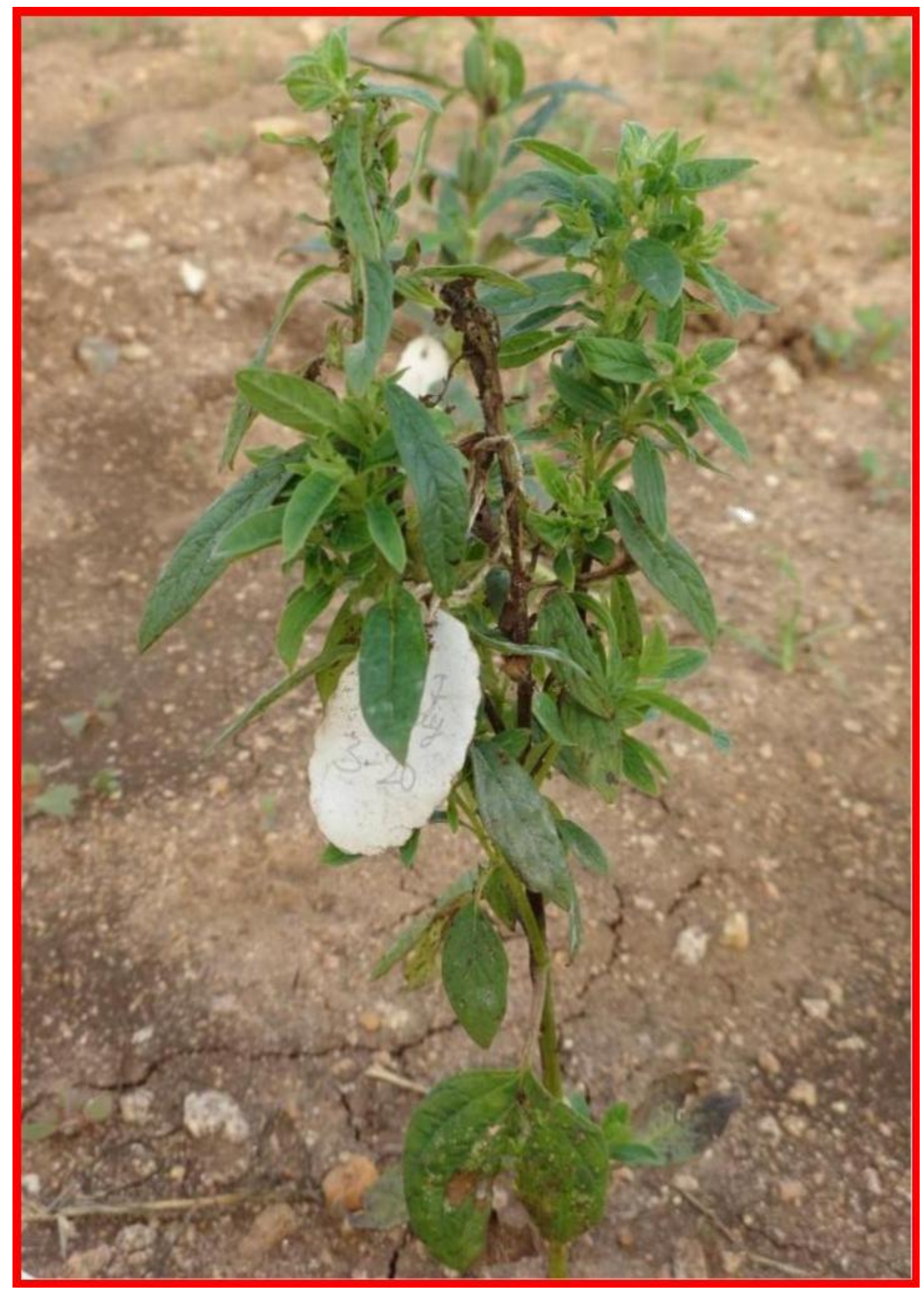

Plate 6. Genotype 19)ES-62 showing virescence symptom 


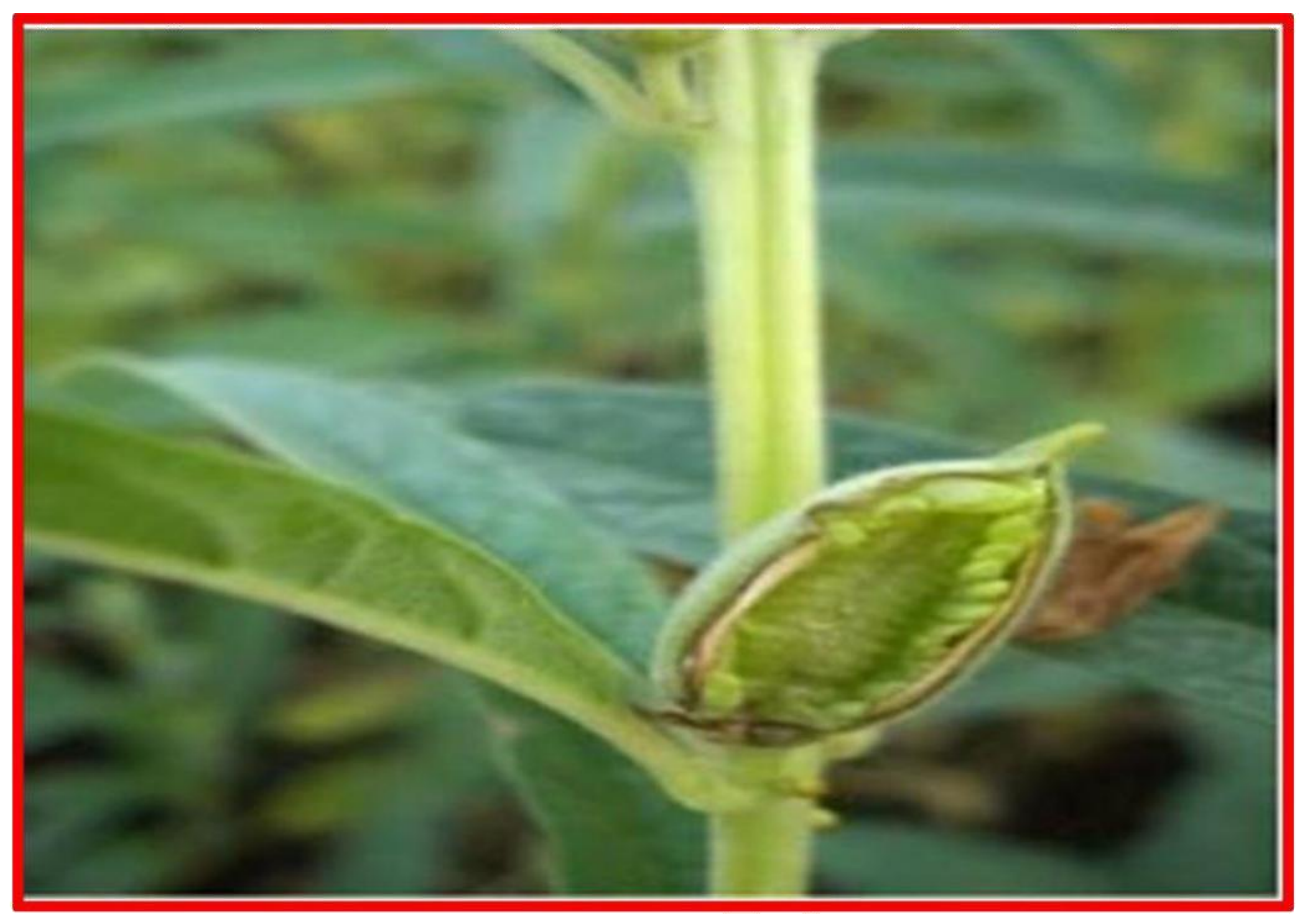

Plate 7. Cracking of capsule longitudinally in genotype 24)JLT-408

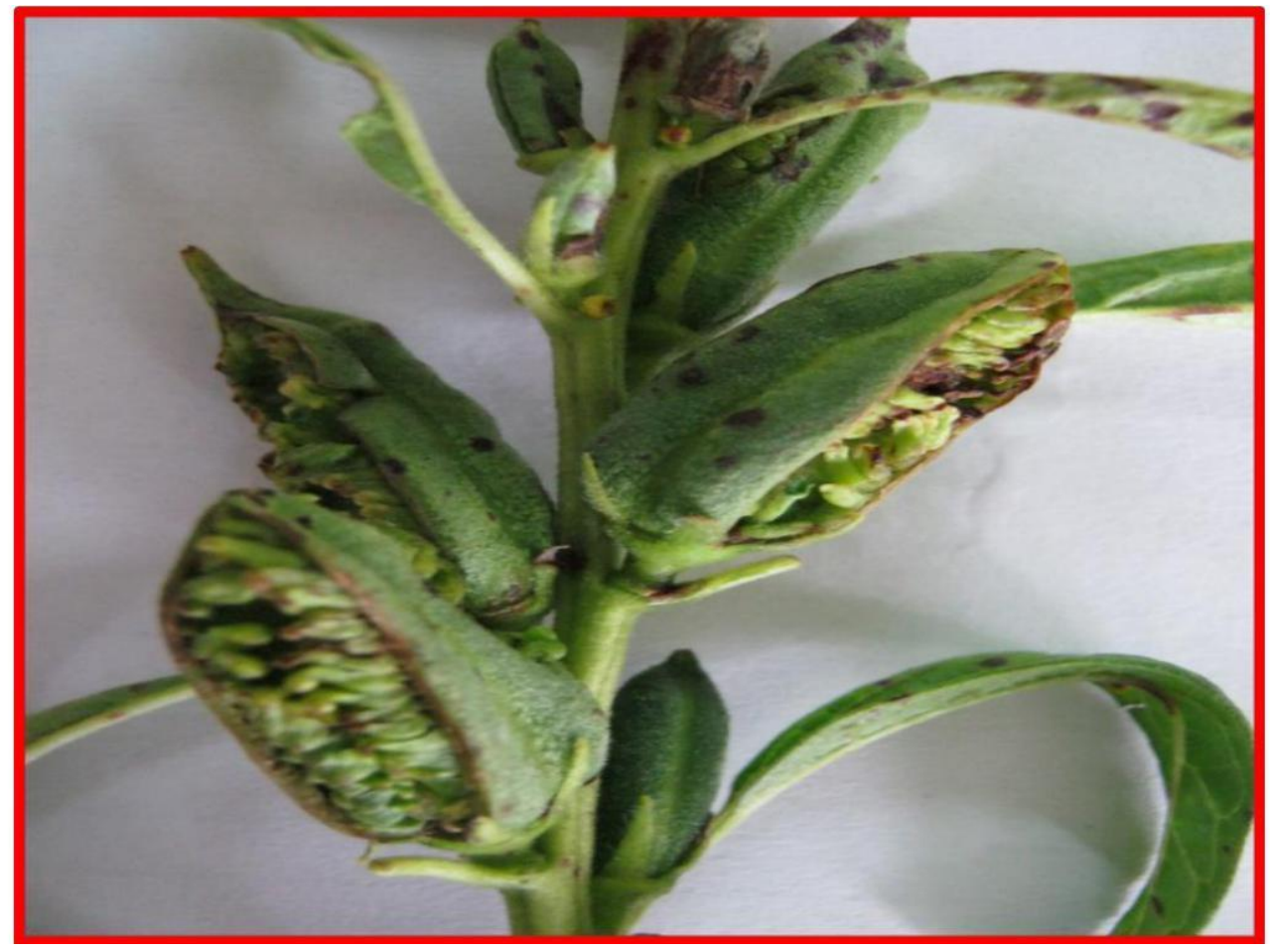

Plate.8 Genotype 17) RT-351 showing vivipary 
Phytoplasmas are known to exhibit a wide range of symptoms in sesamum. The characteristic symptom among the eighteen genotypes was phyllody occurring in eleven genotypes and witches broom in two genotypes.

Combination of symptoms like phyllody and twisting of stem in genotypes 29)G-TIL-10, 26)GRT-8392, phyllody and virescence in genotype 19)ES-62, phyllody and cracking of capsule in genotype 24)JLT-408 and phyllody and vivipary in genotype 17)RT-351 were observed in sesamum genotypes.

The symptoms of phyllody are due to abnormal development of floral parts into leaf like structure caused by phytoplasma. Evidence suggested that phytoplasmas down regulate a gene involved in petal formation, instead causing leaves or leaf like structures to form.

Based on disease scale, two genotypes were highly resistant while one genotype VRI-SV2 was tolerant and rest of the genotypes were moderately susceptible to highly susceptible.

The degree in disease reaction may be due to the genetic makeup of the genotypes resisting the pathogen.

\section{Acknowledgements}

The authors are thankful to Department of Plant Pathology and PJTSAU, Rajendranagar, Hyderabad, Government of India, New Delhi, for providing financial support and ICARIndian Institute of Oilseeds Research for field and laboratory facilities to carry out the research.

\section{References}

Akhtar, K. P., Sarwar, G., Sarwar, N and Elahi, M. T. 2013. Field evaluation of sesame germplasm against sesame phyllody disease. Pakistan Journal of Botany 45:1085-1090.

Banttari, E. E and Zeyea, R. J. 1979. Interactions of mycoplasma like organisms and viruses in dually infected leafhoppers, plant hoppers and plants. Leafhopper Vector and Plant Disease Agents. 6: 327-347.

Bedigian, T. 1985. Sesamin. Sesamoline and the original of sesame biochem systematics. Ecology. 13: 9-133.

Brar, G. S and Ahuja, K. L. 1979. Sesame its culture, genetics, breeding and biochemistry. Annual Review of Plant Physiology. Kalyani Publishers, New Delhi. 245-313.

Cengiz, I., Catal, M., Engin, Y., Rustem, U., Seymus, F., Cengiz, $\mathrm{T}$ and Bulent, U. 2014. Molecular identification, characterization and transmission of phytoplasmas associated with sesame phyllody in Turkey. European Journal of Plant Pathology. 139:217-229.

Choopanya, D. 1973. Mycoplasma like bodies associated with sesamum phyllody in Thailand. Phytopathology. 63:15361537.

Das, A. K and Mitra, D. K. 1998. Detection of mycoplasma-like organisms (MLO's) in sesamum. Indian Phytopathology. 5: 17-20.

Doi, Y., Terenaka, M., Yora, K and Asuyama, H. 1967, Mycoplasma or PLT group like microorganisms found in the phloem elements of plants infected with mulberry dwarf, potato Witche's broom, aster yellows or paulowinias witches broom. Annals of the Phytopathological Society of Japan. 33: 259-266.

El-Bramway and Mahesh. 2010. Genetic analysis of yield component and disease resistance in sesame (Sesame indicum L.) using two progenies of diallel crosses. Research Journal Agronomy. 43: 44-56. 
Lee, I. M and Davis, R. E. 1992. Mycoplasmas which infect insects and plants. In: Mycoplasmas: Molecular biology and pathogenesis. American Society for Microbiology. 609.

Lee, I. M and Davis, R. E. 1992. Mycoplasmas which infect insects and plants. In: Mycoplasmas: Molecular biology and pathogenesis. American Society for Microbiology. 609.

McCoy, R. E., Caudwell, A., Chang, C. J., Chen, T. A., Dale, J. L., Sinha, R. C., Whit comb, R. F., Yang, I. L and Seemuller, E. 1989. Plant disease associated with mycoplasma like organisms. Academic Press. 5:546 640.

Moazzami, A. 2006. Sesame seed lignans. Ph.D. Thesis. Department of Food Science, SLU Acta University Agricultural Scientiae.

Murthy, G. S. S., Joshua, D. C., Rao, N. S and Bhatia, C. R. 1985. Induced mutation in sesame and sunflower: Status and potential, plant production and protection. FAO. 188-190.

Raikwar, R. S and Srivastava, P. 2013. Productivity enhancement of sesame (Sesamum indicum L.) through improved production technologies. African Journal of Agricultural Research. 8(47): 6071-6078.

Ranganatha, A. R. G., Lokesha, R., Tripnthi, A., Asafa, T., Paroha, $\mathrm{S}$ and Srivastava,
M. k. 2012, Sesame improvementpresent status and future strategies. Journal of Oilseeds Research. 29(1): 126.

Salehi, M and Izadpanah, K. 1992. Etiology and transmission of sesame Phyllody in Iran. Journal of Phytopathology. 135: $37-47$.

Singh, P.K., M. Akram, M. Vajpeyi, R.L. Srivastava, K. Kumar and R. Naresh. 2007. Screening and development of resistant sesame varieties against phytoplasm. Bulletin of Insectology. 60: 303-304.

Sudhakar and Rangaswamy, S. 1989. Sesamum Biotechnology: Embryo culture in indicum. Oil Crops News letter. 6: 48-50.

Vasudeva, R. S and Sahambi, H. S. 1955. Phyllody in sesamum (Sesamum orientale L.). Indian Phytopathology. 8:124-129.

Vasudeva, R. S. 1961. Diseases of sesamum. In: Sesamum indicum., Ed Joshi $A B$, Publication, Indian Council Agricultural Research. New Delhi, India. 92-107.

Verma,M. L. 2002. Fungal and Bacterial Diseases of Sesame and their Management Challenges for the Millennium. Jyothi Publication, New Delhi. 161-192.

www.faostat/food/ outlook/2016.com

\section{How to cite this article:}

Vamshi, J., G. Uma Devi, S. Chander Rao and Sridevi, G. 2018. Sesame Phyllody Disease: Symptomatology and Disease Incidence. Int.J.Curr.Microbiol.App.Sci. 7(10): 2422-2437. doi: https://doi.org/10.20546/ijcmas.2018.710.281 